\title{
Neonatal infections in Saudi Arabia: Association with cytokine gene polymorphisms
}

\author{
GAMAL ALLAM ${ }^{1,2}$, ADNAN A. ALSULAIMANI ${ }^{3}$, ALI K. ALZAHARANI ${ }^{3,4}$, AMRE NASR $^{5,6}$ \\ ${ }^{1}$ Department of Microbiology, College of Medicine, Taif University, Taif, Saudi Arabia \\ ${ }^{2}$ Immunology Section, Department of Zoology, Faculty of Science, Beni-Suef University, Beni-Suef, Egypt \\ ${ }^{3}$ Department of Paediatrics, College of Medicine, Taif University, Taif, Saudi Arabia \\ ${ }^{4}$ Department of Neonatology, King Abdel Aziz Specialist Hospital, Taif, Saudi Arabia \\ ${ }^{5}$ Department of Basic Medical Sciences, College of Medicine, King Saud bin Abdulaziz University for Health Sciences, Saudi Arabia, \\ Riyadh, Saudi Arabia \\ ${ }^{6}$ Department of Microbiology, Faculty of Science and Technology, Al-Neelain University, Sudan
}

\begin{abstract}
In recent years, many studies have reported potential associations between cytokine gene polymorphisms and the development, course, and outcome of sepsis, often with apparently conflicting results. The objective of this study was to investigate single nucleotide polymorphism (SNP) in the interleukin (IL)-1 $\beta-31 \mathrm{~T} / \mathrm{C}$, IL-6 - $174 \mathrm{G} / \mathrm{C}$, tumor necrosis factor $\alpha(T N F-\alpha)-308 \mathrm{G} / \mathrm{A}$, and interferon $\gamma(I F N-\gamma)$ +874 A/T genes for their possible association with susceptibility to early onset sepsis (EOS) in Saudi newborn infants. A total of 205 newborn infants aged 1-2 days were consecutively enrolled onto the study having met the inclusion criteria (as per the research protocol). DNA was extracted from filter papers using the Chelex-100 method. The cytokines SNP were genotyping using Taqman 5' nuclease allelic discrimination. For cytokine measurements we used the commercially available Enzyme-Linked Immunosorbent Assay (ELISA) kit. Our results show that the circulating IL-1 $\beta, I L-6, T N F-\alpha$, and IFN- $\gamma$ were significantly $(p<0.001)$ elevated in EOS patients compared to suspected and sepsis-free control groups; and IL-1 $\beta-31 C$, IL-6 -174G, TNF- $\alpha-308 G$, and IFN- $\gamma+874 A$ alleles were associated with EOS in Saudi infants. In conclusion, analysis of cytokines concentrations and SNP for the four tested genes can be used as a predictor of sepsis outcome in newborns.
\end{abstract}

Key words: early onset sepsis, proinflammatory cytokines, single nucleotide polymorphism.

(Centr Eur J Immunol 2015; 40 (1): 68-77)

\section{Introduction}

Sepsis is a host condition of systemic inappropriate inflammatory response to the invasion of microorganisms [1]. Although there are many advances in the development of antibiotics and there has been an explosion of knowledge about the inflammatory response, sepsis still causes one million deaths each year (42\% in the first week of life) [2]. Currently, it is accepted that inappropriate host inflammatory responses or inappropriate defence mechanisms play important roles in the development of sepsis [3-5]. Cytokines play vital roles in the regulation of host immune response, and altered expressions of cytokines are proven to be involved in the development of sepsis [6,7]. Several risk factors for sepsis development have been identified [6], but the cause of basic differences in susceptibility between individuals and populations remains unclear [8]. In recent years, several groups have provided accumulating evidence indicating that the genetic background of the host influences the susceptibility and prognosis of sepsis [9-11]. Previous studies have suggested that the variations in the genes encoding cytokines are involved in the modulation of inflammatory responses and are responsible for inter-individual differences in the susceptibility to sepsis [5]. Recent, epidemiological studies suggest that some single nucleotide polymorphisms (SNP) in the genes encoding inflammatory cytokines may influence the course and outcome of sepsis [5, 12-14]. Exploration of host genetic markers with prognostic value for sepsis might be helpful in managing the neonates who would be most likely to benefit from aggressive antibiotic treatment, and they put the challenges involved into perspective [15]. Therefore, identification of newborns that are at high risk of developing sepsis could help us develop some effective prevention strategies.

Tumour necrosis factor $\alpha$ (TNF- $\alpha$ ), interleukin (IL)-1 $\beta$, and IL-6 are proinflammatory cytokines, which have been

Correspondence: Prof. Gamal Aly Ahmed Allam, College of Medicine, Taif University, 888 Taif, Saudi Arabia, e-mail: gm_allam@yahoo.com 
reported to play important roles in the inflammatory response and in the pathogenesis of sepsis syndrome [16]. The study of IL- $1 \beta$ and TNF- $\alpha$, cytokines that are synthesised at the beginning of the inflammatory cascade, has given differing results. Some studies have reported an increase in the concentrations of these proinflammatory cytokines in systemic circulation in septic newborns [16-20], while others demonstrated similar or even lower levels in infected newborns compared to healthy newborns [21-24]. Such discrepancies in results among different studies could explain the different outcomes of sepsis seen in neonates [25]. Therefore, the variable of clinical evolution of neonatal sepsis is related to the individual variability in cytokine production and intensity of inflammation $[25,26]$, which may be due to the variation of the genetic background of the patients [27].

Results of different published studies addressing the association between the SNP TNF- $\alpha-308$ and development of sepsis in adults and neonates are contradictory. One of the studies suggested that the TNF- $\alpha-308 \mathrm{~A}$ allele has been associated with increased susceptibility to septic shock and mortality from septic shock in adults [28]. However, this association has not been consistently observed [29, 30]. In a study by Hedberg et al. [31] the septic patients presenting the AA/GA genotypes had a mortality rate from sepsis that was three times greater than that seen among those presenting the GG genotype. Moreover, a meta-analysis study has confirmed an increased risk of sepsis in carriers of the A allele for the TNF- $\alpha-308$ $\mathrm{G}>$ A SNP [10]. Regarding IL-1 $\beta$ gene polymorphisms, previous studies indicate that SNPs of IL- $1 \beta$ may be associated with a poor prognosis from sepsis $[32,33]$. However, other studies did not find any association between IL-1 $\beta-31$ polymorphisms and development of bronchopulmonary dysplasia (BPD) in preterm infants [34]. On the other hand, genetic variation within the regulatory part of the IL- 6 gene may affect the incidence and outcome of sepsis $[35,36]$. An association of the IL-6 -174 genotype with sepsis in preterm infants has been reported. Harding et al. reported a higher incidence of the IL-6 -174 GG genotype in infants who developed septicaemia [37]. Similarly, Ahrens et al. reported that the IL-6 -174 GG genotype was more frequent in infants with sepsis compared to infants without infection [38].

Consequently, genetic variability in the regulatory and coding regions of inflammatory cytokine genes may influence the susceptibility and/or outcome of sepsis. We reported in a previous study that a high level of C-reactive protein (CRP) was associated with early onset sepsis (EOS) infection in neonates living in Saudi Arabia, and those babies carrying the A-allele were associated with high levels of circulating CRP [39]. Because IL-1 $\beta$, IL-6, and TNF- $\alpha$ appear before CRP in EOS infection [16-19], such cytokine gene polymorphisms may provide useful biomarkers for the screening of patients at risk, as well as in the identification of those most likely to benefit from specific therapeutic choices [40]. Therefore, the primary aim of the current study was to investigate SNPs in the IL-1 $\beta$-31 T/C (rs1143643), IL-6 -174 G/C (rs1800795), TNF- $\alpha-308$ G/A (rs1800629), and IFN- $\gamma+874$ A/T (rs2430561) genes for their possible association with susceptibility to EOS in Saudi newborn infants. The second aim was to evaluate the association between such SNPs in gene promoter and the circulatory level of corresponding cytokines.

\section{Material and methods}

\section{Study area}

A prospective cohort (cross-sectional) study was carried out over six months, from March to August 2012, in the Neonatal Intensive Care Unit (NICU), King Abdel Aziz Specialist Hospital (KAASH), Taif City, Kingdom of Saudi Arabia (KSA).

\section{Study subject}

A total of 205 newborn infants aged 1-2 days were included in this study. Patients were enrolled if they met the following inclusion criteria for participation in the study: $40 \pm 2$ weeks gestation, an admission to the NICU at KAASH for at least 24 hours, fever $\left(\geq 38.0^{\circ} \mathrm{C}\right.$ measured consecutively on two occasions at least six hours apart), and symptoms or signs of sepsis as described previously $[41,42]$. The subjects were classified into three different groups according to Nasr et al. [39]. Group I is the control group, in which babies have no symptoms or signs of sepsis and a negative blood culture. Controls babies consecutively enrolled to this study, who were admitted to the newborn nursery unit for routine check up within the first two days after birth. Group II is the suspected group of neonates, which includes any infant with signs or symptoms of sepsis, chorioamnionitis, and those born to mothers who had intrapartum temperature $\geq 38.0^{\circ} \mathrm{C}$ or prolonged rupture of membrane $\geq 18$ hours. It is important to note that blood cultures for this group were negative. Once infection was confirmed by means of a positive blood culture, the infant was put into Group III, which is the early onset sepsis (EOS) group.

Babies were clinically examined during their stay in the NICU. Once sepsis was confirmed, blood samples were taken within 12-50 hours after birth. Babies suspected of having sepsis infection, before proven positive culture, were treated by clinicians (neonatologist) with double antibiotics (Ampicilin and Gentamicin) until the baby became symptom free or finished their course of antibiotic. Full blood count was routinely taken. All investigations and treatments were provided free of charge.

\section{Body weight and sample collection}

Newborns were weighed, and those with low birth weight were assessed clinically to differentiate between 
intrauterine growth restriction and low birth weight using the Dubowitiz scoring system.

Before pharmacological treatment was started, $50 \mu \mathrm{l}$ of blood were collected on filter paper (Schleicher $\&$ Schuell; $n^{\circ}$ 903TM) for DNA amplification and quantification of cytokines. Two mls of venous blood was collected in EDTA Vacutainer ${ }^{\circledR}$ tubes (Becton Dickinson, Meylan, France) for bacterial culture.

\section{DNA preparation}

DNA was extracted from filter papers using Chelex-100, which was stored at $-80^{\circ}$ C. $25 \mu$ from peripheral blood or discs of the same size from filter paper were incubated overnight in $1 \mathrm{ml}$ of $0.5 \%$ saponin in PBS at $4{ }^{\circ} \mathrm{C}$, and they were then washed for 15-30 minutes in $1 \mathrm{ml}$ PBS at $4{ }^{\circ} \mathrm{C}$. The discs or the pellets, were boiled in $200 \mu \mathrm{l}$ of 5\% Chelex-100 in water for 15 minutes, and the DNA was collected in supernatants after centrifugation at $250 \times \mathrm{g}$ for 10 minutes [39].

\section{Single nucleotide polymorphism}

The following locations were investigated in this study: IL-1 $\beta$-31 T/C (rs1143643), IL-6 -174 G/C (rs1800795), TNF- $\alpha-308$ G/A (rs1800629), and IFN- $\gamma+874$ A/T (rs2430561) genes. Genotyping was performed with TaqMan $^{\circledR}$ 5' nuclease allelic discrimination (Assay by Design/Demand, Applied Biosystems, Foster City, CA) as described previously [43-45].

\section{Cytokine measurements}

Interleukin $1 \beta$, IL-6, TNF- $\alpha$, and IFN- $\gamma$ levels were estimated by using a high-sensitivity sandwich ELISA kit (Abcam ${ }^{\circledR}$, Cambridge, UK) according to the manufacturer's instructions. Briefly, a monoclonal antibody specific for each cytokine (IL-1 $\beta$, IL-6, TNF- $\alpha$, and IFN- $\gamma$ ) was coated onto the wells of the microtitre plates provided. Samples and standards of known concentrations were applied into the plates. After the incubation period, the biotinylated monoclonal antibodies specific for IL- $1 \beta$, IL-6, TNF- $\alpha$, and IFN- $\gamma$ were added and incubated for one hour. After washing, the enzyme Streptavidin-HRP that binds the biotinylated antibody was added and incubated for one hour at room temperature. A TMB substrate solution was added, and the plates were incubated in the dark for 15 minutes at room temperature. The reaction was stopped by using $2 \mathrm{~N} \mathrm{HCl}$, and the absorbance was measured at $450 \mathrm{~nm}$ using a microplate reader (BioTech, CA, USA). Cytokine concentrations were determined by reference to standard curves construction.

\section{Statistical analysis}

The distribution of cytokines (IL-1 $\beta$, IL- 6 , TNF- $\alpha$, and IFN- $\gamma$ ) genotype, allele frequencies and cytokine (IL- $1 \beta$, IL-6, TNF- $\alpha$, and IFN- $\gamma$ ) concentrations was analysed using
SPSS version 16.0 (SPSS, Inc., Chicago, IL, USA). Using Fisher's exact test, each SNP was tested to determine if the population under investigation showed deviation from genotype frequencies expected under Hardy-Weinberg Equilibrium (HWE) proportions [46]. Tests were performed separately in the cases and controls. Logistic regression analyses were performed to assess associations of genotype (independent variable). Associations were quantified using Odds Ratios [OR] with $95 \%$ confidence intervals (CI), which when they do not cross 1.00 are defined as statistically significant. The (IL-1 $\beta$, IL- 6 , TNF- $\alpha$, and IFN- $\gamma$ ) heterozygote genotypes were used as a reference in the analyses because they were the most frequent genotype in the sepsis-free controls. Using the same software, we performed an overall comparison of allele frequency using a $2 \times 2$ test. The differences in cytokine (IL-1 $\beta$, IL- 6 , TNF- $\alpha$, and IFN- $\gamma$ ) concentrations between different study groups were analysed using Kruskal-Wallis test and the $p$-value was corrected for ties. Logistic regression analyses were performed to assess the association between the cytokine (IL-1 $\beta$, IL- 6 , TNF- $\alpha$, and IFN- $\gamma$ ) serum levels in individuals with different cytokine genotypes. Linkage Disequilibrium (LD) analysis was performed in FStat version 2.9.3.2 to find any haplotype association within the study groups.

\section{Ethical aspects}

This study received ethical clearance from the Ethical Committee of the College of Medicine, Taif University, KSA. Informed consent was obtained from the neonates' parents/legal guardians, who participated in the study after we provided them with adequate information on the objectives and benefits of the project.

\section{Results}

The general characteristics of the study population are presented in Table 1. In Group I, 68 individual had no symptoms for Early Onset Sepsis (EOS) with negative blood culture at a mean \pm standard deviation (SD) age of $1 \pm 0.12$ days. Group II, suspected of EOS: 68 patients had a clinical symptom of EOS with negative blood culture at a mean \pm SD age of $1 \pm 0.12$ days. Group III (EOS): 69 patients had a clinical symptom with positive blood culture at a mean \pm SD age of $1 \pm 0$. The age and sex were matched between the three groups and were not significantly different $(p>0.05$, Table 1$)$.

\section{Cytokine serum levels}

Newborns with sepsis had significantly higher serum levels of pro-inflammatory cytokines (IL-1 $\beta$, IL-6, TNF- $\alpha$, and IFN- $\gamma$ ) compared to both suspected and sepsis-free control groups (overall $p$ value $<0.001$, Table 1 ).

As shown in Table 2, neonates with EOS had significantly higher serum levels of IL- $1 \beta$, IL-6, TNF- $\alpha$, and 
Table 1. Description of the study sex, age, weight and cytokines (IL-1 $\beta$, IL-6, TNF- $\alpha$ and IFN- $\gamma$ pg/ml) levels

\begin{tabular}{lcccc}
\hline Study groups Variables & Sepsis- free controls $\boldsymbol{n}=\mathbf{6 8}$ & Suspected $\boldsymbol{n}=\mathbf{6 8}$ & Early onset sepsis $\boldsymbol{n}=\mathbf{6 9}$ & $\boldsymbol{p}$ value \\
\hline Sex & & & & \\
\hline girls $n(\%)$ & $37(54.4 \%)$ & $25(36.8 \%)$ & 0.06 & \\
\hline boys $n(\%)$ & $31(45.6 \%)$ & $43(63.2 \%)$ & $43(62.3 \%)$ & $<0.091$ \\
\hline Mean \pm SD of: & $1 \pm 0.12$ & $1 \pm 0.12$ & $1 \pm 0(1-1)$ & $<0.001$ \\
\hline age/day & $3608.57 \pm 479.32$ & $2771.96 \pm 200.13$ & $1978.13 \pm 305.50$ & $<0.001$ \\
\hline weight/g & $17.45 \pm 3.177$ & $39.34 \pm 7.80$ & $78.88 \pm 22.0$ & $<0.001$ \\
\hline IL-1 $\beta(\mathrm{pg} / \mathrm{ml})$ & $235.34 \pm 2.59$ & $708.55 \pm 70.57$ & $1263.91 \pm 176.60$ & $<0.001$ \\
\hline IL-6 $(\mathrm{pg} / \mathrm{ml})$ & $8.18 \pm 0.98$ & $16.42 \pm 3.17$ & $39.74 \pm 5.56$ & $<0.001$ \\
\hline TNF- $\alpha(\mathrm{pg} / \mathrm{ml})$ & $12.24 \pm 3.39$ & $35.07 \pm 9.09$ & $91.82 \pm 32.96$ & \\
\hline IFN- $\gamma(\mathrm{pg} / \mathrm{ml})$ & & & & \\
\hline
\end{tabular}

IFN- $\gamma$ compared to the suspected group ( $p$ value $<0.001$, $0.001,0.001$, and 0.001 , respectively).

\section{Cytokine (IL-1 $\beta$, IL-6, TNF- $\alpha$, and IFN- $\gamma$ ) genotypes and allele frequencies}

Genotype frequencies for the candidate SNPs among the study groups with and without sepsis are shown in Table 3 . All polymorphisms analysed in this study were found to be in HWE (data shown in Table 3). The IL-1 $\beta$ CC genotype and allele were associated with EOS compared to suspected patients by unadjusted analysis; for CC genotype: $\mathrm{OR}=6.22,95 \% \mathrm{CI}=(2.11-17.45), p$ value $<0.001$; and for $\mathrm{C}$ allele, $\mathrm{OR}=13.43,95 \% \mathrm{CI}=(7.27-17.45)$, $p$ value $<0.001$ (Table 4). The IL-6 GG and CC genotypes were associated with the EOS patients compared to suspected patients; for GG genotype: $\mathrm{OR}=6.83,95 \%$ $\mathrm{CI}=(3.06-15.22), p$ value $<0.001$; and for CC genotype: $\mathrm{OR}=4.90,95 \% \mathrm{CI}=(1.49-16.15), p$ value $=0.009$ (Table 4). Patients carrying the G allele of the IL-6 were associated with EOS compared to suspected patients; $\mathrm{OR}=1.87,95 \% \mathrm{CI}=(1.11-3.20), p$ value $=0.002(\mathrm{Ta}-$ ble 4). However, no significant association was found in EOS patients carrying the C allele of IL- 6 compared to the suspected group. On the other hand, patients carrying the TNF- $\alpha$ GG genotype and G allele were significantly associated with EOS compared to the suspected group; for GG genotype: $\mathrm{OR}=2.82,95 \% \mathrm{CI}=(1.34-5.97), p$ value $=0.007$; and for the $\mathrm{G}$ allele: $\mathrm{OR}=2.39,95 \% \mathrm{CI}=(1.36$ $4.27), p$ value $=0.001$ (Table 4). The IFN- $\gamma$ AA genotype and allele were associated with EOS when compared to suspected patients by unadjusted analysis; for AA genotype: $\mathrm{OR}=3.27,95 \% \mathrm{CI}=(1.56-6.84), p$ value $=0.002$; and for A allele: $\mathrm{OR}=2.74,95 \% \mathrm{CI}=(1.56-4.90), p$ value $<0.001$ (Table 4).

In addition, we investigated if the cytokine SNPs were in the $L D$. Our results indicated that cytokine SNPs were not in the $L D$ (data not shown) due to the small sample size and the limited risk of losing false negative results.
Table 2. Logistic regression analysis of cytokines (IL-1 $\beta$, IL-6, TNF- $\alpha$ and IFN- $\gamma$ pg/ml) levels in relation to the risk of early onset sepsis compared with suspected patients

\begin{tabular}{lcc}
\hline Cytokines & OR $(\mathbf{9 5 \%}$ CI $)$ & p value \\
\hline IL-1 $\beta$ & $1.25(1.15-1.37)$ & $<0.001$ \\
\hline IL-6 & $1.66(0.72-1.03)$ & 0.001 \\
\hline TNF- $\alpha$ & $7.97(3.40-12.29)$ & 0.001 \\
\hline IFN- $\gamma$ & $1.51(1.18-1.94)$ & 0.001 \\
\hline
\end{tabular}

\section{Analysis of cytokines (IL-1 $\beta$, IL-6, TNF- $\alpha$, and $\mathrm{IFN}-\gamma)$ levels $(\mathrm{pg} / \mathrm{ml})$ in relation to cytokines (IL-1 $\beta$, IL-6, TNF- $\alpha$, and IFN- $\gamma$ ) genotype polymorphisms in the combined study population}

In order to investigate if the cytokine (IL-1 $\beta$, IL-6, TNF- $\alpha$, and IFN- $\gamma$ ) SNPs affected the circulatory level of the corresponding cytokine (IL-1 $\beta$, IL- 6 , TNF- $\alpha$, and IFN- $\gamma$ ), the association between the SNPs and the levels were analysed. As shown in Table 5, there was a significant association between IL-1 $\beta$ CC genotype and the higher concentration of circulating IL- $1 \beta$ cytokine compared to heterozygote IL-1 $\beta$ TC genotype $[\mathrm{OR}=10.33$, $95 \% \mathrm{CI}=(4.71-22.63), p$ value $<0.001]$. The IL-6 GG genotypes were associated with higher level of circulating IL-6 cytokine compared to individuals carrying the heterozygous IL-6 GC genotype $[\mathrm{OR}=2.80,95 \%$ $\mathrm{CI}=(1.51-5.54), p$ value $<0.001$ (Table 5) $]$. Individuals carrying the TNF- $\alpha$ AA genotype were significantly associated with lower level of circulating TNF- $\alpha$ cytokine compared to individuals carrying the TNF- $\alpha$ GA $[\mathrm{OR}=0.36,95 \% \mathrm{CI}=(0.16-0.82), p$ value $=0.014(\mathrm{Ta}-$ ble 5)]. There was a significant association between the individuals carrying IFN- $\gamma$ AA genotypes and the higher concentration of IFN- $\gamma$ cytokine $[\mathrm{OR}=2.78,95 \%$ 
Table 3. Description of cytokines (IL-1 $\beta$, IL-6, TNF- $\alpha$ and IFN- $\gamma$ ) genotypes polymorphism and alleles frequency in the study groups

\begin{tabular}{|c|c|c|c|c|}
\hline Genotypes & $\begin{array}{c}\text { Sepsis-free controls } \\
n=68(\%)\end{array}$ & $\begin{array}{l}\text { Suspected } \\
n=68(\%)\end{array}$ & $\begin{array}{c}\text { Early onset sepsis } \\
n=69(\%)\end{array}$ & $\begin{array}{r}\text { Hardy-Weinberg } \\
\text { equilibrium test }\end{array}$ \\
\hline \multicolumn{5}{|l|}{ IL- $1 \beta$} \\
\hline $\mathrm{TT}$ & $12(17.6 \%)$ & $33(48.5 \%)$ & $5(7.2 \%)$ & \multirow{3}{*}{0.164} \\
\hline $\mathrm{T} / \mathrm{C}$ & $46(67.6 \%)$ & $32(47.1 \%)$ & $12(17.4 \%)$ & \\
\hline $\mathrm{CC}$ & $10(14.7 \%)$ & $3(4.4 \%)$ & $52(75.4 \%)$ & \\
\hline \multicolumn{5}{|c|}{ Alleles frequency* } \\
\hline $\mathrm{T}$ & 0.51 & 0.72 & 0.16 & \\
\hline $\mathrm{C}$ & 0.49 & 0.28 & 0.84 & \\
\hline \multicolumn{5}{|l|}{ IL-6 } \\
\hline $\mathrm{G} / \mathrm{G}$ & $13(19.1 \%)$ & $14(20.6 \%)$ & $39(56.5 \%)$ & \multirow{3}{*}{0.754} \\
\hline $\mathrm{G} / \mathrm{C}$ & $32(47.1 \%)$ & $49(72.1 \%)$ & $20(29.0 \%)$ & \\
\hline $\mathrm{C} / \mathrm{C}$ & $23(38.8 \%)$ & $5(7.4 \%)$ & $10(14.5 \%)$ & \\
\hline \multicolumn{5}{|c|}{ Alleles frequency } \\
\hline G & 0.43 & 0.57 & 0.71 & \\
\hline $\mathrm{C}$ & 0.57 & 0.43 & 0.29 & \\
\hline \multicolumn{5}{|l|}{ TNF- $\alpha$} \\
\hline $\mathrm{G} / \mathrm{G}$ & $11(16.2 \%)$ & $26(38.2 \%)$ & $45(65.2 \%)$ & \multirow{3}{*}{0.587} \\
\hline G/A & $30(44.1 \%)$ & $31(45.6 \%)$ & $19(27.5 \%)$ & \\
\hline $\mathrm{A} / \mathrm{A}$ & $27(39.7 \%)$ & $11(16.2 \%)$ & $5(7.2 \%)$ & \\
\hline \multicolumn{5}{|c|}{ Alleles frequency§ } \\
\hline $\mathrm{G}$ & 0.38 & 0.61 & 0.79 & \\
\hline $\mathrm{A}$ & 0.62 & 0.39 & 0.21 & \\
\hline \multicolumn{5}{|l|}{ IFN- $\gamma$} \\
\hline $\mathrm{A} / \mathrm{A}$ & $7(10.3 \%)$ & $22(32.4 \%)$ & $44(63.8 \%)$ & \multirow{3}{*}{0.514} \\
\hline $\mathrm{A} / \mathrm{T}$ & $26(38.2 \%)$ & $36(52.9 \%)$ & $22(31.9 \%)$ & \\
\hline $\mathrm{T} / \mathrm{T}$ & $35(51.5 \%)$ & $10(14.7 \%)$ & $3(4.3 \%)$ & \\
\hline \multicolumn{5}{|c|}{ Alleles frequency" } \\
\hline A & 0.29 & 0.59 & 0.80 & \\
\hline $\mathrm{T}$ & 0.71 & 0.41 & 0.20 & \\
\hline
\end{tabular}

*Overall $I L-1 \beta$ alleles frequency; OR=1.34; $95 \% C I=(1.07-1.67), p$ value $=0.010$

Overall $I L-6$ alleles frequency; $O R=3.28 ; 95 \% C I=(1.92-5.59), p$ value $<0.001$

$\S$ Overall TNF- $\alpha$ alleles frequency; $O R=5.11 ; 95 \% C I=(1.74-8.01), p$ value $=0.003$

\#Overall IFN- $\gamma$ alleles frequency; $O R=3.23 ; 95 \% C I=(1.65-5.38)$, $p$ value $=0.004)$

$\mathrm{CI}=(1.40-5.50), p$ value $=0.003$ (Table 5) $]$. The lower concentration of IFN- $\gamma$ cytokine was associated with individuals carrying the IFN- $\gamma$ TT genotypes, when compared to those carrying the IFN- $\gamma$ AT genotype $[\mathrm{OR}=0.18,95 \%$ $\mathrm{CI}=(0.76-0.44), p$ value $<0.001$ (Table 5) $]$.

\section{Discussion}

Proinflammatory cytokines play an important role in the immune response, pathogenesis of sepsis, and organ dysfunction [47]. Single nucleotide polymorphisms in cytokine genes may explain, at least to some extent, the variability of the clinical course observed in sepsis and infections. The majority of previous studies related to SNPs in sepsis were performed on adults [36]. However, data from neonate populations with sepsis are poor, and developmental differences that affect inflammation and immune responses make it difficult to extrapolate data from adult studies to newborn populations $[8,48]$. The current study focused on analyses of SNPs in four genes (IL-1 $\beta$ 
Table 4. Logistic regression analysis of cytokines (IL-1 $\beta$, IL-6, TNF- $\alpha$ and IFN- $\gamma$ ) genotypes polymorphism and alleles frequency in early onset sepsis compared with suspected patients

\begin{tabular}{|c|c|c|}
\hline Cytokine genes & OR $(95 \%$ CI $)$ & $p$ value \\
\hline \multicolumn{3}{|l|}{$\mathrm{IL}-1 \beta$} \\
\hline $\mathrm{T} / \mathrm{T}$ & $0.40(0.13-1.28)$ & 0.123 \\
\hline $\mathrm{T} / \mathrm{C}$ & 1.00 & \\
\hline $\mathrm{C} / \mathrm{C}$ & $6.22(2.11-17.45)$ & $<0.001$ \\
\hline \multicolumn{3}{|l|}{ IL-1 $\beta$ allele } \\
\hline $\mathrm{T}$ & \multirow{2}{*}{$13.43(7.27-25.71)$} & \multirow{2}{*}{$<0.001$} \\
\hline $\mathrm{C}$ & & \\
\hline \multicolumn{3}{|l|}{ IL-6 } \\
\hline $\mathrm{G} / \mathrm{G}$ & $6.83(3.06-15.22)$ & $<0.001$ \\
\hline $\mathrm{G} / \mathrm{C}$ & 1.00 & \\
\hline $\mathrm{C} / \mathrm{C}$ & $4.90(1.49-16.15)$ & 0.009 \\
\hline \multicolumn{3}{|l|}{ IL-6 allele } \\
\hline $\mathrm{G}$ & \multirow{2}{*}{$1.87(1.11-3.20)$} & \multirow{2}{*}{0.002} \\
\hline$\overline{\mathrm{C}}$ & & \\
\hline \multicolumn{3}{|l|}{ TNF- $\alpha$} \\
\hline $\mathrm{G} / \mathrm{G}$ & $2.82(1.34-5.97)$ & 0.007 \\
\hline $\mathrm{G} / \mathrm{A}$ & 1.00 & \\
\hline $\mathrm{A} / \mathrm{A}$ & $0.74(0.22-2.46)$ & 0.626 \\
\hline \multicolumn{3}{|l|}{ TNF- $\alpha$ allele } \\
\hline G & \multirow{2}{*}{$2.39(1.36-4.27)$} & \multirow{2}{*}{0.001} \\
\hline $\mathrm{A}$ & & \\
\hline \multicolumn{3}{|l|}{ IFN- $\gamma$} \\
\hline $\mathrm{A} / \mathrm{A}$ & $3.27(1.56-6.84)$ & 0.002 \\
\hline $\mathrm{A} / \mathrm{T}$ & 1.00 & \\
\hline $\mathrm{T} / \mathrm{T}$ & $0.49(0.12-1.98)$ & 0.317 \\
\hline \multicolumn{3}{|l|}{ IFN- $\gamma$ allele } \\
\hline A & \multirow{2}{*}{$2.74(1.56-4.90)$} & \multirow{2}{*}{$<0.001$} \\
\hline $\mathrm{T}$ & & \\
\hline
\end{tabular}

-31 T/C, IL-6 -174 G/C, TNF- $\alpha-308$ G/A, and IFN- $\gamma$ $+874 \mathrm{~A} / \mathrm{T})$ that may play a critical role in, or are associated with, inflammatory response and sepsis severity, in order to identify possible predictive mechanisms for sepsis risk stratification.

Interleukin $1 \beta$ is thought to be one of the key mediators in the pathogenesis of sepsis syndrome $[49,50]$. Data of the present study clearly showed that newborns with EOS had significantly higher serum levels of IL-1 $\beta$ compared with suspected and sepsis-free groups. This finding supports previous studies that have demonstrated an elevated level of IL-1 $\beta$ in plasma of septic neonates when com-
Table 5. Logistic regression analysis of cytokines (IL-1 $\beta$, IL-6, TNF- $\alpha$ and IFN- $\gamma$ ) levels (pg/ml) in relation to cytokines (IL-1 $\beta$, IL-6, TNF- $\alpha$ and IFN- $\gamma$ ) genotypes polymorphism in the combined study population

\begin{tabular}{lcc}
\hline Cytokine genes & OR $(\mathbf{9 5 \%} \mathbf{C I})$ & $\boldsymbol{p}$ value \\
\hline $\mathrm{IL}-1 \beta$ & $1.79(0.88-3.65)$ & 0.108 \\
\hline $\mathrm{T} / \mathrm{T}$ & 1.00 & \\
\hline $\mathrm{T} / \mathrm{C}$ & $10.33(4.71-22.63)$ & $<0.001$ \\
\hline $\mathrm{C} / \mathrm{C}$ & & \\
\hline $\mathrm{IL}-6$ & $2.80(1.51-5.54)$ & 0.001 \\
\hline $\mathrm{G} / \mathrm{G}$ & 1.00 & \\
\hline $\mathrm{G} / \mathrm{C}$ & $0.70(0.32-1.53)$ & 0.371 \\
\hline $\mathrm{C} / \mathrm{C}$ & $1.82(0.97-3.41)$ & 0.061 \\
\hline $\mathrm{TNF}-\alpha$ & 1.00 & \\
\hline $\mathrm{G} / \mathrm{G}$ & $0.36(0.16-0.82)$ & 0.014 \\
\hline $\mathrm{G} / \mathrm{A}$ & & \\
\hline $\mathrm{A} / \mathrm{A}$ & $2.78(1.40-5.50)$ & 0.003 \\
\hline $\mathrm{IFN}-\gamma$ & 1.00 & $<0.001$ \\
\hline $\mathrm{A} / \mathrm{A}$ & $0.18(0.76-0.44)$ & \\
\hline $\mathrm{A} / \mathrm{T}$ &
\end{tabular}

OR represent odds ratios while CI represents confidence intervals. Lower levels of cytokines (IL-1 $\beta, I L-6, T N F-\alpha$, and IFN- $\gamma)$ were assigned 0 ; higher levels of cytokines were assigned 1 in the logistic regression analysis. OR above 1 represented value associated to higher levels of cytokines, while less than 1 value represented lower levels of cytokines.

pared with both healthy infants and infants with clinically suspected but not confirmed sepsis [17, 18]. Therefore, several studies have evaluated the role of this cytokine in the early diagnosis of neonatal sepsis [17-19]. In addition, our data clearly showed a significant association between IL-1 $\beta$ CC genotype and higher concentration of circulating IL-1 $\beta$ cytokine compared to heterozygote IL-1 $\beta$ TC genotype. Also, the IL-1 $\beta$ CC genotype and allele are associated with EOS as compared to suspected patients. Previous data indicates that SNPs of IL-1 $\beta$ may be associated with a poor prognosis from sepsis $[32,33]$. However, other studies did not find any association between IL-1 $\beta$ (C3953T) polymorphisms and outcome of sepsis [34, 51]. Kang et al. [52] concluded that IL-1 $\beta-31$ and IL-1 $\beta-511$ polymorphisms are not associated with the development of bronchopulmonary dysplasia in preterm infants. This discrepancy may be explained by differences in the definition of sepsis and its severity, studied IL- $1 \beta$ SNPs, and in the general characteristics of the enrolled subjects, including ethnicity.

Interleukin 6 plays an important role in the development, pathogenesis, and outcome of sepsis and septic shock. Data from the present investigation clearly demonstrated that neonates with EOS showed a highly significant 
serum level of IL-6 compared to suspected and sepsis-free groups. This finding is in agreement with previous studies that reported that IL-6 is excessively elevated in septic neonates when compared with both healthy infants and infants with clinically suspected but not confirmed sepsis [17]. Many investigators have demonstrated that levels of circulating IL-6 correlate with severity of sepsis and may predict outcome [35, 49, 53, 54]. Interleukin 6 appears to be ideal for detecting early-onset neonatal infection with a high degree of sensitivity and specificity $[18,19,55,56]$. Since IL-6 is a very early marker that appears before CRP, it may be useful in the monitoring of patients with high risk of developing infection.

Genetic variation within the regulatory part of the IL-6 gene may affect the incidence and outcome of sepsis [57]. Our data showed that the IL-6 GG genotypes are associated with EOS when compared to suspected patients, and IL-6 -174G allele is associated with EOS. However, no significant association was found between IL-6 -174C allele and EOS. In addition, the IL-6 GG genotypes are associated with higher levels of circulating IL- 6 cytokine compared to individuals carrying the heterozygous IL-6 GC genotype. This result is in accordance with previous studies suggesting that individuals with IL-6 - 174C allele have significantly lower plasma concentrations of IL-6 [58], and this allele is associated with reduced IL-6 plasma levels in newborns [59]. Bennermo et al. [60] revealed that the IL- $6-174 \mathrm{G}$ allele is functional in vivo with increased inflammatory response. Similar results were found by studies that included Caucasian infants and showed that there was a risk of neonatal sepsis associated with the SNP IL-6 -174 GG [37, 38]. However, contradictory results were seen by Reiman et al. [61] and Baier et al. [62] in studies that included very-low-birth-weight (VLBW) infants of different ethnicities; they showed that the IL-6 -174C allele was associated with increased incidence of sepsis. On the other hand, other studies did not detect any association between the SNP IL-6 -174 and neonatal sepsis [63-65]. Such contradictions in data between various studies could be attributed to the differences in study design, ethnicity, and gene-to-gene and gene-to-environmental interactions [8]. In our study, we reported that the IL-6 $-174 \mathrm{G}$ allele is associated with higher levels of circulating IL-6 and EOS. Consequently, IL-6 gene polymorphisms G-174 > C could be predictors of risk of development and/or predictors of the severity of sepsis in the Saudi newborn population.

Tumor necrosis factor $\alpha$ is recognised as a primary mediator in the pathophysiology of sepsis and septic shock (reviewed in [66]). Data from the current study showed that serum levels of TNF- $\alpha$ were significantly higher in the EOS group compared to suspected and sepsis-free control groups. This result is in accordance with previous studies that demonstrated an elevated serum level of TNF- $\alpha$ on day 1 of neonatal sepsis, and the role of TNF- $\alpha$ as an early diagnostic marker in neonatal sepsis has been evaluated [16-19]. With regards to the SNP in TNF- $\alpha$ gene promoter, the data presented here indicate that patients who are carriers of the $T N F-\alpha$ GG genotype and G allele are significantly associated with EOS patients, compared to the suspected group. Furthermore, individuals carrying the TNF- $\alpha$ AA genotypes are significantly associated with lower levels of circulating TNF- $\alpha$ cytokine, compared to individuals carrying the TNF- $\alpha$ GA genotype. These results are in parallel with the findings of previous studies that have demonstrated a pattern of protection that was conferred by the TNF- $\alpha-308$ GA genotype against both sepsis mortality and acute respiratory distress syndrome (ARDS) outcome in a paediatric population [67]. Similarly, in the adult population, another study has found an association between SNP TNF- $\alpha-308 \mathrm{~A}$ allele and protection against ARDS [68]. However, several studies have reported an association between SNP TNF- $\alpha-308$ G/A and sepsis outcome in the adult and paediatric population [10, 28, 29, 31, 69], while other studies did not show any association between the SNP TNF- $\alpha-308$ G/A and increased risk of sepsis [50, 65, 70]. Such discrepancies in results among different studies could be explained by the variations in study design, enrolled subjects, ethnicity, and gene-to-gene and gene-to-environmental interactions [8]. In addition, Azevedo et al. [67] speculated that $-308 \mathrm{G}>\mathrm{A}$ and $-863 \mathrm{G}>\mathrm{A}$ SNPs in the $T N F-\alpha$ gene promoter seem to work in opposite directions, and could in fact reflect a different impact depending on age.

Data from this study clearly showed high serum IFN- $\gamma$ levels in EOS patients, compared to the suspected and sepsis-free control group. High levels of IFN- $\gamma$ could lead to side-effects such as tachycardia, myalgia, malaise, leucopaenia, and weakness [49]. Interferon $\gamma$ enhances LPS-induced mortality and increases levels of LPS-induced circulating TNF- $\alpha$ [68]; consequently, anti-IFN- $\gamma$ antibodies protected against LPS- and Escherichia coli-induced mortality [71]. In addition, IFN- $\gamma$ was shown to be a mediator of TNF- $\alpha$-induced lethality [72]. Therefore, IFN- $\gamma$ could play an important role in sepsis development and outcome. Our results demonstrated that the IFN- $\gamma$ AA genotype and A allele are associated with EOS when compared to suspected patients. There is a significant association between individuals carrying the IFN- $\gamma$ AA genotype and the higher concentration of IFN- $\gamma$. Individuals carrying the IFN- $\gamma$ TT genotype are associated with lower concentrations of IFN- $\gamma$ when compared to those carrying the IFN- $\gamma$ AT genotype. The IFN- $\gamma+874 \mathrm{~A}$ allele has previously been reported to be associated with some infectious diseases [73-75]. Recently, the IFN $-\gamma+874$ A allele has been shown to be associated with susceptibility to severe acute respiratory syndrome (SARS). Individuals with IFN- $\gamma+874$ AA and AT genotype had a 5.19-fold and 2.57-fold increased risk of developing SARS, respectively [76]. The mechanism by which the IFN- $\gamma+874 \mathrm{~A} / \mathrm{T}$ allele influences the sus- 
ceptibility to sepsis may therefore depend on its role in the regulation of IFN- $\gamma$ production [44].

\section{Conclusions}

In conclusion, circulating IL- $1 \beta$, IL- 6 , TNF- $\alpha$, and IFN- $\gamma$ were elevated in EOS patients; and IL- $1 \beta-31 \mathrm{C}$, IL-6 - 174G, TNF- $\alpha-308 \mathrm{G}$, and IFN- $\gamma+874 \mathrm{~A}$ alleles were associated with EOS in Saudi infants. However, due to the small sample size of this study, the cytokine SNPs were not in the $L D$. Therefore, these results need to be confirmed by a large-scale multicentre prospective study and should be supported by data from other ethnic populations, with the hope that it could be used to develop an early predictor for the prognosis of sepsis in neonates.

\section{The authors declare no conflict of interest.}

We are grateful to Dr. Anhar Yassin, Guils borough Surgery, Northampton, UK for her contribution in improving the science and language of the manuscript. This work was supported by a research grant from Taif University, Kingdom of Saudi Arabia (Number: 1-434-2258).

\section{References}

1. Lagu T, Rothberg MB, Nathanson BH, et al. (2011): The relationship between hospital spending and mortality in patients with sepsis. Arch Intern Med 171: 292-299.

2. Lawn JE, Cousens S, Zupan J (2005): 4 million neonatal deaths: when? Where? Why? Lancet 365: 891-900.

3. Boomer JS, To K, Chang KC, et al. (2011): Immunosuppression in patients who die of sepsis and multiple organ failure. Jama 306: 2594-2605.

4. Kim SD, Lee HY, Shim JW, et al. (2011): Activation of CXCR2 by extracellular matrix degradation product acetylated Pro-Gly-Pro has therapeutic effects against sepsis. Am J Respir Crit Care Med 184: 243-251.

5. Stearns-Kurosawa DJ, Osuchowski MF, Valentine C, et al. (2011): The pathogenesis of sepsis. Annu Rev Pathol 6: 19-48.

6. Cornell TT, Wynn J, Shanley TP, et al. (2010): Mechanisms and regulation of the gene-expression response to sepsis. Pediatrics 125: 1248-1258.

7. Ouyang L, Lv YD, Hou C, et al. (2013): Quantitative analysis of the association between interleukin-10 $1082 \mathrm{~A} / \mathrm{G}$ polymorphism and susceptibility to sepsis. Mol Biol Rep 40: 43274332.

8. Jabandziev P, Smerek M, Michalek J, et al. (2014): Multiple gene-to-gene interactions in children with sepsis: a combination of five gene variants predicts outcome of life-threatening sepsis. Crit Care 18: R1.

9. Chauhan M, McGuire W (2008): Interleukin-6 (-174C) polymorphism and the risk of sepsis in very low birth weight infants: meta-analysis. Arch Dis Child Fetal Neonatal Ed 93: F427-429.

10. Teuffel O, Ethier MC, Beyene J, Sung L (2010): Association between tumor necrosis factor-alpha promoter -308 A/G polymorphism and susceptibility to sepsis and sepsis mortality: a systematic review and meta-analysis. Crit Care Med 38: 276-282.
11. Tiancha H, Huiqin W, Jiyong J, et al. (2011): Association between lymphotoxin-alpha intron +252 polymorphism and sepsis: a meta-analysis. Scand J Infect Dis 43: 436-447.

12. Garnacho-Montero J, Aldabo-Pallas T, Garnacho-Montero C, et al. (2006): Timing of adequate antibiotic therapy is a greater determinant of outcome than are TNF and IL-10 polymorphisms in patients with sepsis. Crit Care 10: R111.

13. Lowe PR, Galley HF, Abdel-Fattah A, Webster NR (2003): Influence of interleukin-10 polymorphisms on interleukin-10 expression and survival in critically ill patients. Crit Care Med 31: 34-38.

14. Zeng L, Gu W, Chen K, et al. (2009): Clinical relevance of the interleukin 10 promoter polymorphisms in Chinese Han patients with major trauma: genetic association studies. Crit Care 13: R188.

15. Härtel C, Schultz C, Herting E, Gopel W (2007): Genetic association studies in VLBW infants exemplifying susceptibility to sepsis - recent findings and implications for future research. Acta Paediatr 96: 158-165.

16. Ozdemir A, Oygur N, Gultekin M, et al. (1994): Neonatal tumor necrosis factor, interleukin-1 alpha, interleukin-1 beta, and interleukin-6 response to infection. Am J Perinatol 11: 282-285.

17. Berner R, Niemeyer CM, Leititis JU, et al. (1998): Plasma levels and gene expression of granulocyte colony-stimulating factor, tumor necrosis factor-alpha, interleukin (IL)-1beta, IL-6, IL-8, and soluble intercellular adhesion molecule-1 in neonatal early onset sepsis. Pediatr Res 44: 469-477.

18. Kurt AN, Aygun AD, Godekmerdan A, et al. (2007): Serum IL-1beta, IL-6, IL-8, and TNF-alpha levels in early diagnosis and management of neonatal sepsis. Mediators Inflamm 2007: 31397.

19. Martin H, Olander B, Norman M (2001): Reactive hyperemia and interleukin 6, interleukin 8, and tumor necrosis factor-alpha in the diagnosis of early-onset neonatal sepsis. Pediatrics 108: E61.

20. Sherwin C, Broadbent R, Young S, et al. (2008): Utility of interleukin-12 and interleukin-10 in comparison with other cytokines and acute-phase reactants in the diagnosis of neonatal sepsis. Am J Perinatol 25: 629-636.

21. Edgar JD, Wilson DC, McMillan SA, et al. (1994): Predictive value of soluble immunological mediators in neonatal infection. Clin Sci (Lond) 87: 165-171.

22. Miller LC, Isa S, LoPreste G, et al. (1990): Neonatal interleukin-1 beta, interleukin-6, and tumor necrosis factor: cord blood levels and cellular production. J Pediatr 117: 961-965.

23. Ng PC, Cheng SH, Chui KM, et al. (1997): Diagnosis of late onset neonatal sepsis with cytokines, adhesion molecule, and $\mathrm{C}$-reactive protein in preterm very low birthweight infants. Arch Dis Child Fetal Neonatal Ed 77: F221-227.

24. Santana Reyes C, Garcia-Munoz F, Reyes D, et al. (2003): Role of cytokines (interleukin-1beta, 6, 8, tumour necrosis factor-alpha, and soluble receptor of interleukin-2) and C-reactive protein in the diagnosis of neonatal sepsis. Acta Paediatr 92: 221-227.

25. Carvalho JK, Moore DB, Luz RA, et al. (2013): Prediction of sepsis-related outcomes in neonates through systematic genotyping of polymorphisms in genes for innate immunity and inflammation: a narrative review and critical perspective. Sao Paulo Med J 131: 338-350.

26. Levy O, Martin S, Eichenwald E, et al. (1999): Impaired innate immunity in the newborn: newborn neutrophils are 
deficient in bactericidal/permeability-increasing protein. Pediatrics 104: 1327-1333.

27. Deasy A, Read RC (2010): Genetic variation in pro-inflammatory cytokines and meningococcal sepsis. Curr Opin Infect Dis 23: 255-258.

28. Mira JP, Cariou A, Grall F, et al. (1999): Association of TNF2, a TNF-alpha promoter polymorphism, with septic shock susceptibility and mortality: a multicenter study. Jama 282: 561-568.

29. Read RC, Teare DM, Pridmore AC, et al. (2009): The tumor necrosis factor polymorphism TNF (-308) is associated with susceptibility to meningococcal sepsis, but not with lethality. Crit Care Med 37: 1237-1243.

30. Stuber F, Udalova IA, Book M, et al. (1995): -308 tumor necrosis factor (TNF) polymorphism is not associated with survival in severe sepsis and is unrelated to lipopolysaccharide inducibility of the human TNF promoter. J Inflamm 46: 42-50.

31. Hedberg CL, Adcock K, Martin J, et al. (2004): Tumor necrosis factor alpha -- 308 polymorphism associated with increased sepsis mortality in ventilated very low birth weight infants. Pediatr Infect Dis J 23: 424-428.

32. Walley AJ, Aucan C, Kwiatkowski D, Hill AV (2004): Interleukin-1 gene cluster polymorphisms and susceptibility to clinical malaria in a Gambian case-control study. Eur J Hum Genet 12: 132-138.

33. Pociot F, Molvig J, Wogensen L, et al. (1992): A TaqI polymorphism in the human interleukin-1 beta (IL-1 beta) gene correlates with IL-1 beta secretion in vitro. Eur J Clin Invest 22: 396-402.

34. Jessen KM, Lindboe SB, Petersen AL, et al. (2007): Common TNF-alpha, IL-1 beta, PAI-1, uPA, CD14 and TLR4 polymorphisms are not associated with disease severity or outcome from Gram negative sepsis. BMC Infect Dis 7: 108.

35. Hack CE, De Groot ER, Felt-Bersma RJ, et al. (1989): Increased plasma levels of interleukin-6 in sepsis. Blood 74: 1704-1710.

36. Sutherland AM, Walley KR (2009): Bench-to-bedside review: Association of genetic variation with sepsis. Crit Care 13: 210.

37. Harding D, Dhamrait S, Millar A, et al. (2003): Is interleukin-6 -174 genotype associated with the development of septicemia in preterm infants? Pediatrics 112: 800-803.

38. Ahrens P, Kattner E, Kohler B, et al. (2004): Mutations of genes involved in the innate immune system as predictors of sepsis in very low birth weight infants. Pediatr Res 55: 652-656.

39. Nasr A, Allam G, Al-Zahrani A, Alsulaimani A (2013): Neonatal infections in Saudi Arabia: association with C-reactive protein, CRP -286 (C>T>A) gene polymorphism and IgG antibodies. BMC Immunol 14: 38.

40. Marshall JC, Reinhart K (2009): Biomarkers of sepsis. Crit Care Med 37: 2290-2298.

41. Kaftan H, Kinney JS (1998): Early onset neonatal bacterial infections. Semin Perinatol 22: 15-24.

42. Belady PH, Farkouh LJ, Gibbs RS (1997): Intra-amniotic infection and premature rupture of the membranes. Clin Perinatol 24: 43-57.

43. Wilson AG, Symons JA, McDowell TL, et al. (1997): Effects of a polymorphism in the human tumor necrosis factor alpha promoter on transcriptional activation. Proc Natl Acad Sci U S A 94: 3195-3199.

44. Pravica V, Perrey C, Stevens A, et al. (2000): A single nucleotide polymorphism in the first intron of the human IFN-gamma gene: absolute correlation with a polymorphic
CA microsatellite marker of high IFN-gamma production. Hum Immunol 61: 863-866.

45. Abu-Maziad A, Schaa K, Bell EF, et al. (2010): Role of polymorphic variants as genetic modulators of infection in neonatal sepsis. Pediatr Res 68: 323-329.

46. Trikalinos TA, Salanti G, Khoury MJ, Ioannidis JP (2006): Impact of violations and deviations in Hardy-Weinberg equilibrium on postulated gene-disease associations. Am J Epidemiol 163: 300-309.

47. Dong GH, Gong JP, Li JZ, et al. (2013): Association between gene polymorphisms of IRAK-M and the susceptibility of sepsis. Inflammation 36: 1087-1093.

48. Wynn J, Cornell TT, Wong HR, et al. (2010): The host response to sepsis and developmental impact. Pediatrics 125 : 1031-1041.

49. Cavaillon JM (1998): Pathophysiological Role of Pro- and Anti-Inflammatory Cytokines in Sepsis. Sepsis 2: 127-140.

50. Härtel C, Hemmelmann C, Faust K, et al. (2011): Tumor necrosis factor-alpha promoter -308 G/A polymorphism and susceptibility to sepsis in very-low-birth-weight infants. Crit Care Med 39: 1190-1195.

51. Fang XM, Schroder S, Hoeft A, Stuber F (1999): Comparison of two polymorphisms of the interleukin-1 gene family: interleukin-1 receptor antagonist polymorphism contributes to susceptibility to severe sepsis. Crit Care Med 27: 1330-1334.

52. Kang JH, Lee JJ, Cho S, et al. (2013): Association of Interleukin- $1 \alpha-889, \beta-31, \beta-511$ Polymorphism with Risk of Bronchopulmonary Dysplasia. Neonatal Med 20: 413-421.

53. Calandra T, Gerain J, Heumann D, et al. (1991): High circulating levels of interleukin-6 in patients with septic shock: evolution during sepsis, prognostic value, and interplay with other cytokines. The Swiss-Dutch J5 Immunoglobulin Study Group. Am J Med 91: 23-29.

54. Waage A, Brandtzaeg P, Halstensen A, et al. (1989): The complex pattern of cytokines in serum from patients with meningococcal septic shock. Association between interleukin 6, interleukin 1, and fatal outcome. J Exp Med 169: 333-338.

55. Kuster H, Weiss M, Willeitner AE, et al. (1998): Interleukin-1 receptor antagonist and interleukin- 6 for early diagnosis of neonatal sepsis 2 days before clinical manifestation. Lancet 352: 1271-1277.

56. Messer J, Eyer D, Donato L, et al. (1996): Evaluation of interleukin-6 and soluble receptors of tumor necrosis factor for early diagnosis of neonatal infection. J Pediatr 129: 574-580.

57. Michalek J, Svetlikova P, Fedora M, et al. (2007): Interleukin-6 gene variants and the risk of sepsis development in children. Hum Immunol 68: 756-760.

58. Fishman D, Faulds G, Jeffery R, et al. (1998): The effect of novel polymorphisms in the interleukin-6 (IL-6) gene on IL-6 transcription and plasma IL-6 levels, and an association with systemic-onset juvenile chronic arthritis. J Clin Invest 102: 1369-1376.

59. Kilpinen S, Hulkkonen J, Wang XY, Hurme M (2001): The promoter polymorphism of the interleukin- 6 gene regulates interleukin-6 production in neonates but not in adults. Eur Cytokine Netw 12: 62-68.

60. Bennermo M, Held C, Stemme S, et al. (2004): Genetic predisposition of the interleukin- 6 response to inflammation: implications for a variety of major diseases? Clin Chem 50: 2136-2140.

61. Reiman EM, Chen K, Caselli RJ, et al. (2008): Cholesterol-related genetic risk scores are associated with hypometab- 
olism in Alzheimer's-affected brain regions. Neuroimage 40: 1214-1221.

62. Baier RJ, Loggins J, Yanamandra K (2006): IL-10, IL-6 and $\mathrm{CD} 14$ polymorphisms and sepsis outcome in ventilated very low birth weight infants. BMC Med 4: 10.

63. Abdel-Hady H, El-Naggar M, El-Nady G, et al. (2009): Genetic polymorphisms of IL-6-174 and IL-10-1082 in full term neonates with late onset blood stream infections. J Pediatr Infect Dis 4: 357-365.

64. Gopel W, Hartel C, Ahrens P, et al. (2006): Interleukin-6-174-genotype, sepsis and cerebral injury in very low birth weight infants. Genes Immun 7: 65-68.

65. Treszl A, Kocsis I, Szathmari M, et al. (2003): Genetic variants of TNF-[FC12]a, IL-1beta, IL-4 receptor [FC12]a-chain, IL-6 and IL-10 genes are not risk factors for sepsis in lowbirth-weight infants. Biol Neonate 83: 241-245.

66. Wong HR (2012): Genetics and genomics in pediatric septic shock. Crit Care Med 40: 1618-1626.

67. Azevedo ZM, Moore DB, Lima FC, et al. (2012): Tumor necrosis factor (TNF) and lymphotoxin-alpha (LTA) single nucleotide polymorphisms: importance in ARDS in septic pediatric critically ill patients. Hum Immunol 73: 661-667.

68. Heinzel FP (1990): The role of IFN-gamma in the pathology of experimental endotoxemia. J Immunol 145: 2920-2924.

69. Nadel S, Newport MJ, Booy R, Levin M (1996): Variation in the tumor necrosis factor-alpha gene promoter region may be associated with death from meningococcal disease. J Infect Dis 174: $878-880$.

70. Schueller AC, Heep A, Kattner E, et al. (2006): Prevalence of two tumor necrosis factor gene polymorphisms in premature infants with early onset sepsis. Biol Neonate 90: 229-232.

71. Silva AT, Cohen J (1992): Role of interferon-gamma in experimental gram-negative sepsis. J Infect Dis 166: 331-335.

72. Doherty GM, Lange JR, Langstein HN, et al. (1992): Evidence for IFN-gamma as a mediator of the lethality of endotoxin and tumor necrosis factor-alpha. J Immunol 149: 1666-1670.

73. Ben-Ari Z, Mor E, Papo O, et al. (2003): Cytokine gene polymorphisms in patients infected with hepatitis B virus. Am J Gastroenterol 98: 144-150.

74. Kerr JR, McCoy M, Burke B, et al. (2003): Cytokine gene polymorphisms associated with symptomatic parvovirus B19 infection. J Clin Pathol 56: 725-727.

75. Tso HW, Ip WK, Chong WP, et al. (2005): Association of interferon gamma and interleukin 10 genes with tuberculosis in Hong Kong Chinese. Genes Immun 6: 358-363.

76. Chong WP, Ip WK, Tso GH, et al. (2006): The interferon gamma gene polymorphism $+874 \mathrm{~A} / \mathrm{T}$ is associated with severe acute respiratory syndrome. BMC Infect Dis 6: 82. 